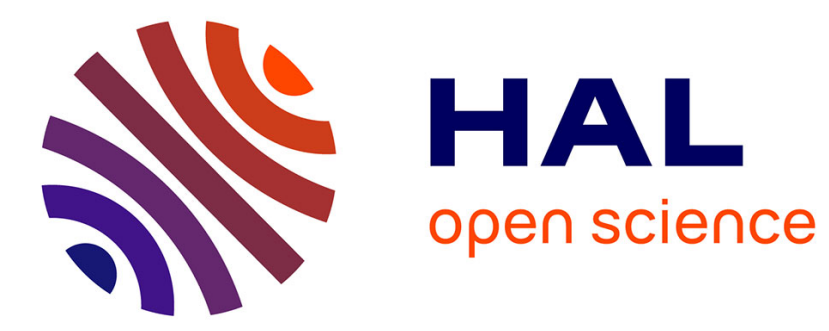

\title{
Christianisme, identités culturelles et communautés en Polynésie française
}

\author{
Yannick Fer, Gwendoline Malogne-Fer
}

\section{To cite this version:}

Yannick Fer, Gwendoline Malogne-Fer. Christianisme, identités culturelles et communautés en Polynésie française. HERMES Cognition, communication, Politique $n^{\circ} 32-33$. LA FRANCE ET LES OUTRE-MERS : L'ENJEU MULTICULTUREL, CNRS EDITIONS, p. 355 à 366., 2002. halshs00120101

\section{HAL Id: halshs-00120101 https://shs.hal.science/halshs-00120101}

Submitted on 13 Jun 2015

HAL is a multi-disciplinary open access archive for the deposit and dissemination of scientific research documents, whether they are published or not. The documents may come from teaching and research institutions in France or abroad, or from public or private research centers.
L'archive ouverte pluridisciplinaire HAL, est destinée au dépôt et à la diffusion de documents scientifiques de niveau recherche, publiés ou non, émanant des établissements d'enseignement et de recherche français ou étrangers, des laboratoires publics ou privés. 
Yannick Fer

Université de la Polynésie française

Gwendoline Malogne-Fer

EHESS

\section{CHRISTIANISME, IDENTITÉS CULTURELLES ET COMMUNAUTÉS EN POLYNÉSIE FRANÇAISE}

En Polynésie française, les appartenances religieuses participent pour une part essentielle à la construction des identités individuelles et collectives. Malgré un relatif affaiblissement des pratiques institutionnalisées, notamment la participation aux cultes, et l'émergence d'une catégorie se définissant comme " sans religion ", le christianisme occupe une place déterminante non seulement dans la société polynésienne, mais aussi dans ce qui est considéré comme l'identité culturelle « traditionnelle » des communautés qui la composent.

L'âge d'or ressemble, pour beaucoup de Tahitiens, à ces temps qui, dans la Genèse, précèdent la destruction de la tour de Babel, lorsque « la terre entière se servait de la même langue et des mêmes mots " (Genèse 11:1), comme dans ces îles éloignées où l'identité insulaire se confond encore avec une appartenance religieuse, et la communauté avec son église. 
Mais aujourd'hui, en particulier à Tahiti où vit $70 \%$ de la population, l'offre religieuse est très diverse et les appartenances très dispersées, $\mathrm{y}$ compris au sein des familles où coexistent souvent, avec plus ou moins de difficultés, différentes confessions.

L'évolution économique et sociale du Territoire, son entrée à marche forcée dans la modernité occidentale et la concentration croissante de la population sur l'île de Tahiti ont affaibli les repères qui permettaient de définir les appartenances communautaires : les identités familiales, insulaire et religieuse se sont en partie diluées dans un mode de vie plus urbanisé, plus individualisé, dans ce "processus de dé-totalisation de l'expérience humaine qui résulte de la différenciation des institutions » (Hervieu-Léger, 1999,p. 61). Les identités, les appartenances qui « allaient de soi " hier sont aujourd'hui largement recomposées, recréées : on en hérite moins facilement, on les choisit de plus en plus.

En même temps que s'accentuait cette modernisation de la société polynésienne, les deux églises historiques dominantes — l'église évangélique de Polynésie française (EEPF), protestante, et l'église catholique - ont apporté leur concours à des tentatives de réactivation ou de renforcement d'identités communautaires. Soit que l'église se définisse comme un élément structurant de la tradition (l'EEPF et la culture polynésienne ou ma'ohi), soit qu'elle accueille et protège une culture minoritaire (l'église catholique et la communauté chinoise).

Comment concilier la visée universelle du christianisme avec l'exigence d'un enracinement dans les cultures locales ? Toutes les églises chrétiennes missionnaires ont eu à réfléchir à l'articulation entre l'annonce de l'Évangile et la culture pré-chrétienne des peuples convertis ${ }^{1}$. Comme le souligne $\mathrm{C}$. Geffré, " le problème que pose l'inculturation du christianisme » — définie par B. Chenu comme « une transposition de la problématique de l'incarnation au niveau de la rencontre foi chrétienne et culture non chrétienne » (cité par Hoiore, 1992, p. 108) — est de savoir si " l'étrangeté du message chrétien provient de la nouveauté radicale de l'Évangile ou du véhicule culturel auquel le christianisme historique est nécessairement lié » $(1984$, p. 8).

L'incorporation du christianisme aux cultures communautaires polynésiennes suppose inévitablement que ces églises se donnent une définition de ces cultures qu'elles entendent aujourd'hui respecter. Or, dans la culture polynésienne pré-missionnaire, mais aussi dans la culture chinoise traditionnelle, « la religion est partout : elle n'est pas séparée de l'ensemble des rapports sociaux et des pratiques sociales " (Hervieu-Léger, 1999, p. 20). Dès lors, comment préserver la culture tout en évacuant les anciennes croyances?

Le discours de l'EEPF s'appuie sur un processus historique de « tressage » entre la tradition culturelle et la Bible qui a aujourd'hui plus de deux cents ans, tressage qui tend à intégrer la majeure partie des croyances religieuses pré-missionnaires dans une " continuité ", en les interprétant comme une sorte de "christianisme primitif ».Une approche que l'on ne retrouve pas dans la petite communauté chinoise protestante. À l'opposé, l'église catholique, qui n'affiche pas le même militantisme culturel ma'ohi, a créé, pour la communauté chinoise, la seule paroisse extra-territoriale, et élaboré, à partir des années 1960, une combinaison entre la lignée croyante 
ancestrale (le culte des ancêtres, défini comme une pratique culturelle non religieuse) et la foi catholique.

\section{Le paysage religieux polynésien : territorialisation et dispersion des appartenances}

\section{Religion et territoires}

Les « îles éloignées " ${ }^{2}$ vivent, dans l'imaginaire tahitien contemporain, comme un « mythe à l'intérieur du mythe ", symboles d'une identité traditionnelle préservée 3 .

Dans ces archipels, l'appartenance religieuse est très homogène : les îles Australes sont à $80 \%$ protestantes, les îles Marquises, les Tuamotu et les Gambier à $90 \%$ catholiques. Cette forte territorialisation des identités religieuses témoigne, jusqu'à aujourd'hui, d'une histoire missionnaire dont l'enjeu était tout autant la conquête des territoires que le salut des âmes.

L'évangélisation initiée par les missionnaires protestants de la London Missionary Society à la fin du XVIII e siècle a d'abord contribué à la domination de " la religion des anglais ", appellation que la tutelle de la société des missions de Paris (en 1863) puis l'autonomie de l'EEPF (en 1963) n'ont jamais effacée des mémoires polynésiennes. Alors que l'instauration du protectorat français en 1843 , contribua à créer des conditions très favorables au renforcement de l'implantation des frères catholiques présents depuis 1834 aux îles Gambier.

Cet affrontement, à la fois religieux et territorial, a fait de l'église, dans les îles éloignées, un repère identitaire fort : on était supposé protestant si on était rurutu, catholique si on était marquisien, tandis que Tahiti apparaissait divisée, entre les deux églises " historiques ", puis entre la multitude des confessions religieuses apparues au cours des $\mathrm{XIX}^{\mathrm{e}}$ et $\mathrm{XX}^{\mathrm{e}}$ siècles.

\section{Tabiti et les églises minoritaires}

Le dernier recensement officiel de la Polynésie française comportant la question de l'appartenance religieuse date de 1971 . L'église protestante rassemblait alors $51 \%$ des Polynésiens, $47 \%$ des habitants de Tahiti et l'église catholique, avec $34 \%$ des Polynésiens, $38 \%$ des habitants de Tahiti.

Aujourd'hui, la diversité des églises représentées à Tahiti ne doit pas masquer la domination toujours effective de ces deux églises historiques.

Il est assez difficile d'évaluer avec précision le poids des différentes confessions, comme a tenté de le faire un récent sondage de l'institut Louis Harris ${ }^{4}$. Aujourd'hui, on peut estimer qu'environ $80 \%$ de ceux qui, à Tahiti, se reconnaissent une religion d'appartenance appartiennent (dans un 
rapport proche de 40/40) à l'église catholique ou à l'EEPF Les $20 \%$ restant se répartissent entre les différentes religions minoritaires, que nous présenterons en indiquant — faute d'évaluations plus précises - les chiffres issus du sondage Louis Harris.

Les missionnaires mormons, arrivés dès 1844, ont contribué à l'implantation en Polynésie française de deux églises qui occupent, par rapport aux identités communautaires polynésiennes, deux positions nettement différentes.

L'Église de Jésus-Christ des saints des derniers jours (7\%), «mormone ", doit une bonne part de l'attrait qu'elle exerce sur une partie de la population tahitienne à son rattachement à « la puissante Amérique » (Simon, 1984, p. 74), souligné par la présence de jeunes « elders » américains.

Au contraire, l'Église mormone réorganisée 5 ( $3 \%$ ), connue en Polynésie (et en NouvelleCalédonie) sous le nom de sanito, autonome depuis 1973 vis-à-vis de l'église mère du Missouri, apparaît aujourd'hui profondément polynésienne, du fait de "l'absence de missionnaires popa'a " et par "ses assemblées à forte dominante ma'obi " (Simon, 1984, p. 75). Son implantation ancienne dans les Tuamotu contribue à cet enracinement identitaire, qui contraste nettement avec le profil plutôt indifférencié des autres églises minoritaires.

L'Église adventiste du $7^{\mathrm{e}}$ jour $(6 \%)$, protestante, se distingue d'abord par l'observation stricte du sabbat et d'interdits alimentaires (proscription de l'alcool, du tabac, mais aussi de la viande de porc). Cette orientation correspond tout particulièrement à l'expérience sociale d'une classe moyenne supérieure, polynésienne mais surtout "demie", comme le rappelle " l'engagement actif de certains membres à des postes administratifs à responsabilité (éducation, enseignement, santé, services sociaux...) » (Martin, 1990, p. 142).

Les témoins de Jéhovah (2\%), présents depuis 1958, se sont aujourd'hui implantés dans tous les archipels. Initiée par deux couples américains, leur action missionnaire a été ensuite menée par un couple local — un américain marié à une tahitienne - aidé, dès 1960, par des « pionniers spéciaux » français. G. Simon notait en 1984 : « le fait qu'une seule congrégation de Tahiti soit en langue tahitienne montre bien que popa'a et demis sont nombreux ; la communauté chinoise est aussi assez bien représentée » (p. 99).

Enfin, depuis le début des années 1980, le protestantisme charismatique connaît une progression rapide, à travers l'Église évangélique de Pentecôte, ou assemblées de Dieu, dans l'ensemble des îles de la Société. Essentiellement polynésiennes dans les îles, ces assemblées accueillent une proportion importante de popa'a et de chinois sur Tahiti. L'influence de cette tendance, qui compte encore peu de fidèles, tient beaucoup aux émissions que diffuse depuis quatre ans sa station de radio, te vevo o te tiaturira'a ( "l'écho de l'espoir »).

Pour compléter ce panorama de la diversité religieuse polynésienne, il faut encore mentionner un certain nombre de mouvements d'inspiration chrétienne, comme l'Église de Tahiti, issue en 1979 d'une scission de la communauté protestante chinoise et dont le prophète actuel, Elie Hong, vit sur le mont Sion à Taïwan, ainsi qu'une nébuleuse mystique-ésotérique ${ }^{6}$. 


\section{Dispersion et fluidité}

Ce paysage religieux est animé d'une double dynamique : dispersion et fluidité. Comme l'a souligné J.-F. Baré, la plupart des Polynésiens croient en l'existence d'une seule vérité divine : "l'une des plaisanteries coutumières des Polynésiens contemporains est de répéter inlassablement que les pasteurs sont des menteurs - 'orometua ha'avare - pour la raison première que, s'il existe une vérité divine, elle ne saurait être incarnée par différentes confessions " $(1987$, p. 32). Dieu est un, les églises sont multiples. Pour beaucoup de Polynésiens, la recherche de la " vraie » ou de la « bonne » religion se traduit par des adhésions successives à plusieurs églises et parfois par la participation simultanée à différents cultes.

L'appartenance (par lignée familiale surtout) aux églises « historiques " ne valant pas nécessairement pleine adhésion aux croyances religieuses qu'elles définissent, ce cheminement peut aboutir à dissocier la religion « dans laquelle on est né » et celle que l'on s'est choisie, en conciliant parfois la fidélitéà la religion familiale avec un intérêt spirituel pour les enseignements d'une autre confession.

Car au sein de familles où coexistent de plus en plus souvent différentes confessions, ce parcours religieux est aussi une quête identitaire, qui fait ou défait les liens héréditaires symboliques : quitter la religion de son père pour celle de sa mère, c'est choisir l'une contre l'autre.Identités familiale, communautaire et religieuse tendent à se disjoindre, à se disperser. À l'exception de certaines îles éloignées, les églises ne rassemblent que rarement toute une communauté culturelle ou insulaire. Et que l'on se déclare chinois, ma'obi, popa'a ou demi, ce repère ne donne aucune équivalence stricte en termes d'appartenance religieuse.

\section{"Dieu aime l'babitant de la terre ma'ohi ": l'EEPF, la Bible et la culture ma'ohi}

\section{La Bible au cour de la vie communautaire}

En écrivant l'histoire de la traduction de la Bible en tahitien, J. Nicole a montré combien il était essentiel, pour mener à bien leur projet d'enseigner la Bible en langue vernaculaire, que les missionnaires protestants reconnaissent - à travers notamment l'art oratoire et les chants - la valeur de la culture polynésienne, qu'ils avaient d'abord rejetée. Maîtriser la langue tahitienne (ou reo ma'obi) supposait cette véritable " conversion culturelle, voire spirituelle " sans laquelle ils n'auraient pu « mettre en chantier ce qui restera à tout jamais le monument littéraire et la référence ultime du reo ma'obi classique : la Bible tahitienne » $(1988$, p. 61$)$.

Et c'est à travers cette parole de Dieu qui est aussi parole ma'ohi que s'est nouée la relation historique entre le protestantisme et la culture polynésienne : placer la langue à l'abri de la Bible, c'était aussi y inscrire la tradition et l'identité ma'obi. Il restait aux générations successives la charge d'interpréter cette " parole de vie ", en actualisant sans cesse une mémoire dont les racines, plantées en terre biblique, puisent dans une culture pré-missionnaire. 
Par l'interprétation de la Bible, les paroisses protestantes ont fait naître une identité à la fois traditionnelle et chrétienne qui sert jusqu'à aujourd'hui de repère culturel. Beaucoup se souviennent avec nostalgie des interminables tuaro' $i$, ces réunions consacrées à l'exégèse de versets bibliques, instituées par les missionnaires et devenues le lieu par excellence de ce tressage entre Bible et tradition. La communauté rassemblée y construisait une représentation de son unité par la différence : l'accumulation des interprétations, passées et présentes, faisait émerger un ensemble de vérités complémentaires, un patrimoine commun qui donnait sens à l'existence du groupe.

Les activités quotidiennes - cultiver, pêcher, se nourrir - devenaient vocation, devoir d'assurer l'abondance à travers la terre natale, te fenua, qui donne la vie. Dans cette lecture traditionnelle de la Bible, basée sur la recherche des concordances entre les récits bibliques et la vie quotidienne polynésienne (méthode dite taipe), la communauté se confond avec le peuple élu découvrant la terre promise. Et le Nouveau Testament est lu avant tout comme le renouvellement de l'alliance entre Dieu et son peuple, scellée par le sacrifice du fils qui, répété lors de la sainte cène, assure l'abondance, la fertilité du fenua ${ }^{7}$.

\section{La mémoire protestante revisitée}

Cette combinaison d'éléments culturels polynésiens avec le message protestant est née de la vie communautaire, marquée par une dépendance étroite envers les ressources de la terre et de la mer.

À Tahiti, à partir des années 1960, le développement d'une société de consommation et de salariat, ainsi que les grands chantiers (aéroport, routes, constructions) ont attiré les travailleurs des îles éloignées, tandis que le salariat s'étendait aux archipels ${ }^{8}$. Même si les paroisses de Tahiti ont accueilli beaucoup des exilés au sein de amuira'a (regroupements intra-paroissiaux) constitués par origine insulaire, le mode de vie protestant traditionnel en a été fragilisé : le départ des jeunes générations, l'affaiblissement des pratiques vivrières ont affaibli la pertinence sociale de ses pratiques et de son message.

Cet effacement progressif de la culture communautaire s'est accompagné de tentatives « de remobilisation et de recréation de la mémoire " (Hervieu-Léger, 1993, p. 208), renouveau culturel qui, dans l'église protestante, a pris la forme d'un « retour aux sources ", c'est-à-dire au temps de la rencontre entre missionnaires et Polynésiens.

Portée par une nouvelle génération de théologiens, dont la figure emblématique est aujourd'hui Turo Raapoto, cette démarche cherche à dissocier le message de l'Évangile du " véhicule culturel auquel le christianisme historique est nécessairement lié ". Non seulement le $M a^{\prime} o b i$ peut recevoir l'Évangile sans renoncer à sa culture mais c'est même la volonté de Dieu : "Dieu aime l'habitant de la terre ma'obi, il veut qu' il soit bien comme il est, dans ses coutumes, et il est venu le voir chez lui, lui a parlé sa langue, a voulu le libérer » (traduction, Saura, 1989, p. 4). 
Réinterprétation moderne et militante de la tradition, ce discours n'impute pas l'effacement de la culture ma'obi aux seuls bouleversements de l'après CEP, mais à une tendance initiée par les missionnaires eux-mêmes, "qui s'empressèrent de ranger la tradition du côté du Mal et de choisir de nouvelles valeurs (...) pour le peuple ma'obi » (Saura, 1989, p. 10).

C'est dire que ce discours ne rejoint pas entièrement la tradition protestante insulaire. Théologie moderne et tradition pratiquante se retrouvent dans la valorisation de la terre, de la langue et du mode de vie $m a^{\prime} o b i$, mais s'opposent lorsqu'il s'agit de déterminer les éléments de la sainte cène : quand cette théologie veut remplacer le pain et le vin par le uru (arbre à pain) et l'eau de coco au nom de la tradition, les anciens rappellent que la tradition, c'est le pain et le vin.

\section{Dieu, Taaroa et les marae}

L'opposition des « anciens » et des " modernes » se joue autour d'une même " source " : les premiers temps de la rencontre entre missionnaires et Polynésiens. Mais les « anciens » ont intégré les enseignements et les pratiques missionnaires (l'habillement, la liturgie, etc.) dans une tradition dont sont exclus certains éléments du passé, en particulier tout ce qui concerne les anciens lieux de culte, les marae. Les " modernes ", au risque de s'opposer à leurs aînés, (pourtant considérés généralement comme les derniers témoins d'une mémoire authentique), retiennent de ces premiers temps de la conversion l'idée que Dieu est venu rencontrer les Polynésiens « dans leur culture ». Relisant l'action missionnaire qui a suivi comme un facteur d'acculturation radicale, ils tendent ainsi à relativiser l'importance historique de l'arrivée de l'Évangile et l'idée même de conversion pour insister davantage sur l'idée que le peuple ma'obi était, depuis toujours, "suivi par Dieu ". Pour mener à bien cette entreprise, Turo Raapoto s'appuie sur une analyse attentive du recueil de traditions, légendes et chants polynésiens établi au début du XIX ${ }^{e}$ siècle par le missionnaire J.M. Orsmond ${ }^{9}$, afin de construire une représentation dans laquelle les temps anciens apparaissent finalement comme une sorte d' "Ancien Testament ma'obi ".

L'accent est en effet mis sur les prophéties annonçant l'arrivée des missionnaires - tout comme les prophètes de l'Ancien Testament avaient annoncé la « nouvelle alliance »-, sur les correspondances entre marae et temple, ou entre le dieu créateur polynésien Taaroa et le dieu Jéhovah.Ce discours identitaire de l'Église évangélique rencontre des résistances parmi les membres des paroisses dites " polynésiennes ». Mais l'Église demeure une référence identitaire grâce au maintien d'une vie paroissiale et communautaire. Cette structuration, qui repose sur un maillage serré de l'espace, permet aux paroissiens de se regrouper par quartier ou par origine (amuira'a), par groupes d'intérêts (tomite) et de vivre certains aspects valorisés de la culture ma'obi à travers les concours de chants et de danses. Cette culture vivante est à la fois l'occasion de se retrouver et le point de repère d'une recherche identitaire sans cesse retravaillée. 


\section{"Soyons $100 \%$ chinois " : l'Église catholique et la communauté chinoise}

\section{Protestants et chinois}

En revanche, le discours identitaire de l'église évangélique n'est pas porteur de sens pour les fidèles chinois. Cette communauté protestante chinoise, surtout présente à Tahiti, s'est d'abord constituée autour de l'école protestante Viénot et de la paroisse de Béthel ${ }^{10}$, à Papeete, avant de donner naissance en 1964 à une paroisse spécifiquement chinoise, la paroisse de Jourdain. Les premiers immigrés, arrivés à partir de 1863 avaient érigé dès 1876 dans le quartier de Mamao un temple bouddhiste dédié à Kan Ti, héros de l'époque des rois royaumes. La communauté chinoise, majoritairement hakka, issue d'un milieu rural très modeste (Hermann, 1976, p. 136) y pratiquait le culte des ancêtres, perpétuant ainsi la lignée familiale et la fidélité à la tradition. Dans l'entre-deux-guerres, les jeunes chinois ont néanmoins intégré les écoles chrétiennes, considérées comme les plus à même d'assurer leur réussite sociale. La plus grande partie ont ainsi été baptisés catholiques, une condition sine qua non pour entrer à l'école des frères, tandis qu'une minorité se tournait vers l'enseignement protestant et intégrait par là l'école du dimanche à Béthel. Renforcée par une vague d'évangélisation au début des années 1960, la communauté qui se retrouve aujourd'hui dans la paroisse de Jourdain confesse une fois évangélique, basée sur une lecture littérale de la Bible, qui privilégie le Nouveau Testament et met l'accent sur la nouvelle identité du converti « en Christ ".

Elle ne renonce pas pour autant à concilier la foi chrétienne et l'identité culturelle hakka. Mais en distinguant culture et religion, elle s'éloigne à la fois de la théologie ma'obi de l'EEPF (qui aurait pu servir de canevas à une théologie hakka polynésienne) et de toute forme de syncrétisme visant à intégrer le culte des ancêtres, les horoscopes ou encore la danse du dragon au christianisme. En opposant culture et religion, elle évacue ce que, dans la culture chinoise, elle considère comme religieux, c'est-à-dire non chrétien, pour conserver essentiellement la langue hakka.

\section{Chinois et catboliques}

Dans le sillage du concile Vatican II, « prônant le respect des cultures et l'utilisation des langues locales »(Hermann, 1979, p. 217) et avec le concours de prêtres chinois ${ }^{11}$, l'église catholique a mis en place, en Polynésie française, une paroisse extra-territoriale chinoise au sein de laquelle a émergé une articulation entre culture et religion nettement différente.

La distinction entre ces deux domaines vise ici moins à exclure qu'à intégrer : les pratiques traditionnelles - et même la fréquentation du temple $\mathrm{Kan} \mathrm{Ti}$ — sont en effet " sécularisées ", requalifiées comme « culturelles », c'est-à-dire non religieuses. Le message catholique adressé à la communauté chinoise se rapproche ainsi, in fine, du discours « ma'obi » de l'EEPF. 
Le 23 janvier 2001 à l'église Maria no te hau, avait lieu une messe de célébration du nouvel an chinois. Sur le parvis, on a pu voir les dragons danser devant Monseigneur Coppenrath, archevêque de Tahiti, tandis que dans son sermon, un prêtre chinois déclarait :

« En Chine, il y a eu un conflit entre les Jésuites et les Dominicains. Les Jésuites comprennent la culture chinoise, ils comprennent que Confucius n'a rien à voir avec la religion. Les Dominicains, c'est le contraire. Les missionnaires ont souffert parce qu'ils ne comprenaient pas la langue, la culture. Cet esprit occidental supérieur a fait beaucoup de mal. Il faut laisser les catholiques aller au temple chinois, surtout nos anciens, il faut laisser une place pour la culture ». Et de conclure : « il faut vraiment devenir un chinois véritable, pas un chinois $1 \%$, pas seulement les vêtements, un chinois $100 \% »$.

Ce discours permet de contourner ce qui a été très longtemps l'obstacle majeur à la conversion au christianisme de la communauté chinoise : la promesse faite aux anciens de toujours perpétuer la mémoire ancestrale, qui se trouvait toute entière inscrite dans des pratiques indissociablement culturelles et religieuses. Renier ces pratiques, c'était renier sa lignée et son identité.

La démarche de l'église catholique (pour l'identité culturelle chinoise) et de l'EEPF (pour la tradition ma'obi) se présentent à première vue comme des entreprises de conservation du patrimoine culturel. Mais elles pourraient bien être tout autant — au même titre que la progression des nouveaux mouvements religieux — une des formes paradoxales d'un processus qui, peu à peu, fait entrer la Polynésie française dans la modernité religieuse définie par D. Hervieu-Léger, où les individus « construisent eux-mêmes, en référence à la continuité d'une lignée croyante quelconque, une identité personnelle qui les constitue comme sujets de leur propre histoire » (2001, p. 96).

\section{NOTES}

1. Pour désigner ce processus, les anthropologues ont souvent utilisé les termes de syncrétisme ou d'acculturation, les hommes d'église utilisant plus volontiers le terme d'inculturation.

2. C'est-à-dire tous les archipels hors les îles de la Société.

3. Partant en 1980 pour Rurutu, dans l'archipel des Australes, J.-C. Guillebaud écrivait : « Rurutu, mieux qu'aucune île de la région, c'est vrai, symbolise encore la fidélité aux traditions polynésiennes, la vigueur d'une culture paysanne dont Papeete, enjazzée et pervertie, quête désespérément le souvenir. Mais cette culture est aujourd'hui toute entière rassemblée autour du clocher protestant, pénétrée de la Bible, animée par les pasteurs $"(1980$, p. 50).

4. Notamment parce que la pratique et la signification du baptême varient très nettement selon les églises : on ne peut considérer comme équivalents le nombre de baptisés enfants et celui des baptisés adultes (dans les églises où le baptême est vécu comme une re-naissance). Sondage publié dans La Dépếche de Tabiti des lundi 11 et mardi 12 septembre 2000 . 
5. L'Église réorganisée de Jésus-Christ des saints des derniers jours est née en 1860 d'une scission de l'Église mormone, fondée en 1830 par Joseph Smith. Son histoire en Polynésie française a été retracée par B. SAURA (1994).

6. Pour une présentation de ce type de nouveaux mouvements religieux, voir par exemple CHAMPION, 1990.

7. Voir Fer \& Malogne-Fer, 2001.

8. Essentiellement à travers l'implantation des collèges et le développement des structures communales, des services de l'équipement et de l'agriculture.

9. Recueil repris et achevé par sa petite-fille T. HENRY (Henry, 1997).

10. Fondée en 1820 pour les résidents et les voyageurs de langue anglaise, cette paroisse indépendante est devenue en 1886 une paroisse de langue française, prise en charge par les missionnaires de la mission évangélique de Paris. Elle a été reconnue comme paroisse de plein exercice au sein de l'EEPF en 1960.

11. L'ordination du premier prêtre chinois de Tahiti a eu lieu en 1964.

\section{RÉFÉRENCES BIBLIOGRAPHIQUES}

BARÉ, J.-F., Tabiti, les temps et les pouvoirs, pour une anthropologie bistorique du Tabiti post-européen, Paris, ORSTOM, 1987.

Champion, F., « La nébuleuse mystique-esotérique ", in Champion, F. \& Hervieu-LÉGer, D. (dir.), De l'émotion en religion, renouveaux et traditions, Paris, Centurion, 1990.

Fer, Y. \& MAlOGNe-Fer, G., Tuaroi, réflexions bibliques à Rapa, conversion et identité, Papeete, Haere po, 2001.

GefFré, C., «Introduction ", in GefFré, C. (éd.), Théologie et choc des cultures, Paris, Éditions du CERF, 1984.

Guillebaud, J.-C., Un voyage en Océanie, Paris, Le Seuil, 1980.

Henry, T., Tabiti aux temps anciens, traduit de l'anglais, Paris, Société des océanistes, 1997.

Hermann, B. \& Association Wen Fa, Histoire et portrait de la communauté chinoise de Tabiti, Papeete, C. Gleizal, 1979.

HeRVIEu-LÉGer, D., La religion pour mémoire, Paris, Éditions du CERF, 1993.

Hervieu-LÉGer, D., Le pèlerin et le converti, la religion en mouvement, Paris, Flammarion, 1999.

HeRvieu-LÉGER, D., La religion en miettes ou la question des sectes, Paris, Calmann Lévy, 2001.

Horore, J., "Sotériologie et théologie de l'inter-religieux/culturel polynésien-océanien ", thèse de doctorat, faculté de théologie de Montpellier, 1992.

Nicole, J., Au pied de l'écriture, bistoire de la traduction de la Bible en tabitien, Papeete, Haere po no Tahiti, 1988. 
SAURA, B., "Théologie de la libération et théologie de la culture chez Duro Raapoto ", BSEO, 246, 1989, pp. 1-15.

SAURA, B., Les Sanito, histoire de l'Église réorganisée de Jésus-Christ des saints des derniers jours en Polynésie française, Independence (Missouri), 1994.

SIMON, G., Religions chrétiennes minoritaires à Tabiti, Papeete, 1984. 